\title{
Pilot evaluation of PD-1 inhibition in metastatic cancer patients with a history of liver transplantation: the Mayo Clinic experience
}

\author{
Thomas T. DeLeon ${ }^{1}$, Marcela A. Salomao ${ }^{2}$, Bashar A. Aqel ${ }^{3}$, Mohamad B. Sonbol ${ }^{1}$, Raquel T. Yokoda ${ }^{1}$, \\ Ahmad H. Ali ${ }^{3}$, Adyr A. Moss ${ }^{4}$, Amit K. Mathur ${ }^{4}$, David M. Chascsa ${ }^{3}$, Jorge Rakela ${ }^{3}$, Alan H. Bryce ${ }^{1}$, \\ Mitesh J. Borad ${ }^{1,5,6}$
}

${ }^{1}$ Division of Hematology \& Oncology, Department of Medicine, ${ }^{2}$ Division of Anatomic Pathology \& Laboratory Medicine, Department of Pathology, ${ }^{3}$ Division of Gastroenterology and Hepatology, Department of Medicine, ${ }^{4}$ Division of Hepatobiliary and Pancreatic Surgery, Department of Surgery, Mayo Clinic, Scottsdale, AZ, USA; ${ }^{5}$ Department of Molecular Medicine, Mayo Clinic, Rochester, MN, USA; ${ }^{6}$ Mayo Clinic Cancer Center, Phoenix, AZ, USA

Contributions: (I) Conception and design: MJ Borad, AH Bryce, TT DeLeon; (II) Administrative support: MA Salomao; (III) Provision of study materials or patients: MJ Borad, TT DeLeon, AH Bryce, BA Aqel, DM Chascsa; (IV) Collection and assembly of data: TT DeLeon; (V) Data analysis and interpretation: MJ Borad, TT DeLeon, AH Bryce, MA Salomao; (VI) Manuscript writing: All authors; (VII) Final approval of manuscript: All authors.

Correspondence to: Mitesh J. Borad, MD. Mayo Clinic, 5777 E Mayo Blvd, Phoenix, AZ, USA. Email: Borad.Mitesh@Mayo.edu.

Background: Patients with solid organ transplants (SOTs) have been excluded from programmed death protein-1 (PD-1)/programmed death ligand-1 (PD-L1) inhibitor clinical trials due to concern for allograft rejection. The use of immune checkpoint inhibitor therapy remains controversial in transplant patients.

Methods: A retrospective pilot evaluation was conducted to assess the safety and efficacy of PD-1 inhibitors in patients with liver transplantation (LT). The primary endpoint was the rate of allograft rejection. Secondary endpoints included overall response rate (ORR), progression free survival (PFS) and overall survival (OS). Translational objectives included evaluation of tumor PD-L1, tumor infiltrating lymphocytes (TILs) and allograft PD-L1 expression.

Results: Seven metastatic cancer patients with a history of LT who received PD-1 inhibitor therapy were included [hepatocellular carcinoma (HCC), n=5; melanoma, n=2]. Rejection was observed in 2 of 7 patients. When rejection occurs it appears to be an early event with a median time to rejection of 24 days in our cohort. One patient achieved a complete response (CR), 3 patients had progressive disease (PD) and 3 patients discontinued therapy prior to restaging assessments. Two of five patients with available tissue had PD-L1 expression in the allograft and both developed rejection. One of five evaluable patients had abundant TILs. Two of five evaluable patients had PD-L1 tumor staining. The single patient with both abundant TILs and PD-L1 staining obtained a response. The median OS and PFS were 1.1 (0.3-21.1) and 1.8 (0.7-21.1) months, respectively.

Conclusions: In this pilot evaluation both preliminary efficacy ( 1 of 4 ) and allograft rejection (2 of 7) were exhibited in evaluable patients. Larger, prospective trials are needed to elucidate optimal patient selection.

Keywords: Immunotherapy; liver transplantation (LT); hepatocellular carcinoma (HCC); melanoma; graft rejection

Submitted May 16, 2018. Accepted for publication Jun 27, 2018.

doi: 10.21037/jgo.2018.07.05

View this article at: http://dx.doi.org/10.21037/jgo.2018.07.05 


\section{Introduction}

The success of programmed death protein-1 (PD-1) inhibitors in cancer therapy has led to an expanding relevance of immunotherapy in oncology (1). However, the safety and efficacy of PD-1 inhibitors in cancer patients with a solid organ transplant (SOT) has remained controversial. Preclinical models have demonstrated that PD-1 and its ligand programmed death ligand-1 (PD-L1) are essential components of both graft induction and maintenance of immune tolerance (2-4). Several murine models have shown that blockade of the PD-1/PD-L1 pathway leads to accelerated graft rejection in cardiac transplants among major histocompatibility complex (MHC) mismatched mice $(3,5)$. Rejection following PD-1/PD-L1 blockade was associated with activation of cellular immunity through $\mathrm{CD}^{+}$effector cells and downregulation of regulatory $\mathrm{T}$ cells (3). On the contrary, PD-L1 expression in the donor graft appeared to have a protective effect against graft rejection $(2,6)$.

Given the valid concern for graft rejection, patients with a SOT have thus far been excluded from cancer immunotherapy clinical trials. Additionally, it is unclear if the effectiveness of cancer immunotherapy is dampened by immunosuppression therapy. Several studies have assessed the safety and efficacy of checkpoint inhibitors in bone marrow transplant patients and have demonstrated that both graft versus host disease and clinical benefit can occur after introduction of checkpoint inhibitors including PD-1 inhibitors (7-9).

Recent case reports have examined the safety of checkpoint inhibitors in SOT patients. A compilation of existing reports showed that graft rejection occurred in 4 out of 12 SOT patients who received checkpoint inhibitors including PD-1 inhibitors and cytotoxic T-lymphocyteassociated protein-4 (CTLA-4) inhibitors (10). The aforementioned literature review included 2 cases of liver transplantation (LT) patients who received CTLA-4 inhibitor therapy, but no LT patients who received PD-1 inhibitors.

According to United Network for Organ Sharing (UNOS) data, hepatocellular carcinoma (HCC) patients who undergo LT have a 5-year OS of $62 \%$ (11). However, HCC recurrence following LT occurs frequently with recurrence rates ranging from $6.9-35.9 \%$ at 5 years of follow up (12). The lack of safety data for the use of checkpoint inhibitors after LT deprives post-LT patients with HCC recurrence the opportunity to be considered for checkpoint inhibitors. Recently, the United States Food and Drug Administration (FDA) approved nivolumab, a PD-1 inhibitor, for advanced HCC who have previously received sorafenib (13). There is an urgent need to evaluate whether checkpoint inhibitors, such as PD-1 inhibitors, can safely salvage HCC that recurs after LT. There are 8 cases reported in which $\mathrm{PD}-1$ inhibitors were used following a LT, of which 2 cases experienced graft rejection (14-16). So far there are only 3 cases that have examined the use of PD-1/PD-L1 inhibitors in HCC patients with a previous LT. This pilot study encompasses the largest single center compilation of LT patients who were treated with PD-1 inhibitors, including HCC patients.

\section{Methods}

\section{Study design}

Retrospective data for this single center pilot study were collected from Mayo Clinic Arizona from April 1, 2016 to April 3, 2018. Patients were identified through physician referral and queries through I2B2 (Informatics for Integrating Biology and the Bedside) and ACE (Advanced Cohort Explorer) search programs. The date ranges were set between March 1, 2007 to March 31, 2017 for both the $\mathrm{I} 2 \mathrm{~B} 2$ and ACE searches. Participants were required to have received a LT and subsequently, PD-1 or PDL1 inhibitor therapy for advanced, recurrent or de novo malignancy. The primary objective was to evaluate the incidence of graft rejection with PD-1/PD-L1 inhibitor therapy. Secondary endpoints include the overall response rate $(\mathrm{ORR})$ with $\mathrm{PD}-1 / \mathrm{PD}-\mathrm{L} 1$ inhibitor therapy, the effect of immunosuppression therapy on rejection and response, clinical outcomes such as progression free survival (PFS), overall survival (OS) and duration of therapy. ORR was determined by RECIST v1.1 criteria. Patients were categorized as complete response (CR), partial response $(\mathrm{PR})$, stable disease $(\mathrm{SD})$ or progressive disease (PD) with regards to best response obtained. Exploratory endpoints included changes in liver function tests [aspartate aminotransferase (AST), alanine aminotransferase (ALT), international normalized ratio (INR), total bilirubin, albumin], tumor marker [alpha-fetoprotein (AFP)] and liver prognostic scores [Model for End Stage Liver Disease (MELD), Child-Turcotte-Pugh] with immunotherapy and the incidence of tumor infiltrating lymphocytes (TILs) and PD-L1 expression in the tumor and allograft. PDL1 expression in the tumor and TILs were correlated 


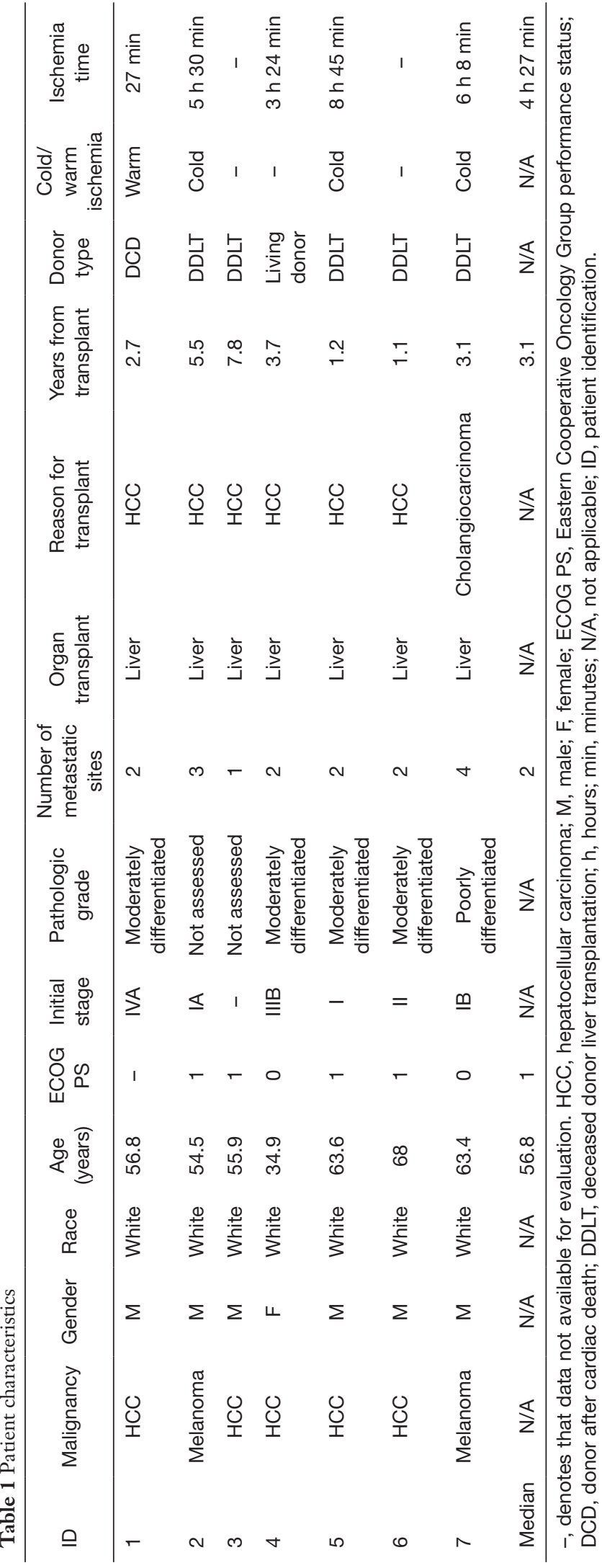

with ORR to PD-1/PD-L1 inhibitors. PD-L1 staining in the liver allograft tissue was correlated with rates of graft rejection.

\section{PD-L1 staining and TILs}

Patients with sufficient pathologic specimen of their liver allograft tissue and tumor tissue underwent PD-L1 staining and evaluation for TILs. PD-L1 staining was performed with the Ventana PD-L1 antibody (SP263) according to the manufacturer's instructions. Tumor PD-L1 status was determined by the percentage of tumor cells with any membrane staining above background of tumor-associated immune cells. Similarly, allograft PD-L1 expression was determined by the percentage of allograft lymphocytes with membrane PD-L1 staining. PD-L1 positivity was defined as tumor or allograft lymphocyte staining $\geq 1 \%$. TILs were measured as the percentage of TILs present above background tumor-associated lymphocytes. Given the exploratory nature of TILs in HCC there was no threshold for high versus low TILs.

\section{Results}

\section{Patient characteristics}

Seven metastatic cancer patients were identified who had a history of LT and subsequently received PD-1 inhibitor therapy and their characteristics are summarized in Table 1. The study cohort included patients with HCC $(n=5)$ and melanoma $(n=2)$. Patients received nivolumab $(n=5)$ and pembrolizumab $(n=2)$. All of the patients in this cohort received previous treatments. The median number of previous therapies was two. All HCC patients had previously received sorafenib. The immunosuppressive agents used in this study are shown in Table 2.

\section{Clinical outcomes}

Four patients were evaluable for response to PD-1 inhibitor therapy. Responses included PD ( $n=3)$ and CR $(n=1)$. The patient with a CR (patient \#2) had metastatic melanoma and discontinued therapy after 9.5 months because of clinical remission (Figure 1) and remains in remission. Three patients required early discontinuation of their therapies because of graft rejection ( $n=2)$ and development of multiorgan failure unrelated to PD-1 inhibition $(\mathrm{n}=1)$. Graft rejection was confirmed with a liver biopsy. Patient \#2 


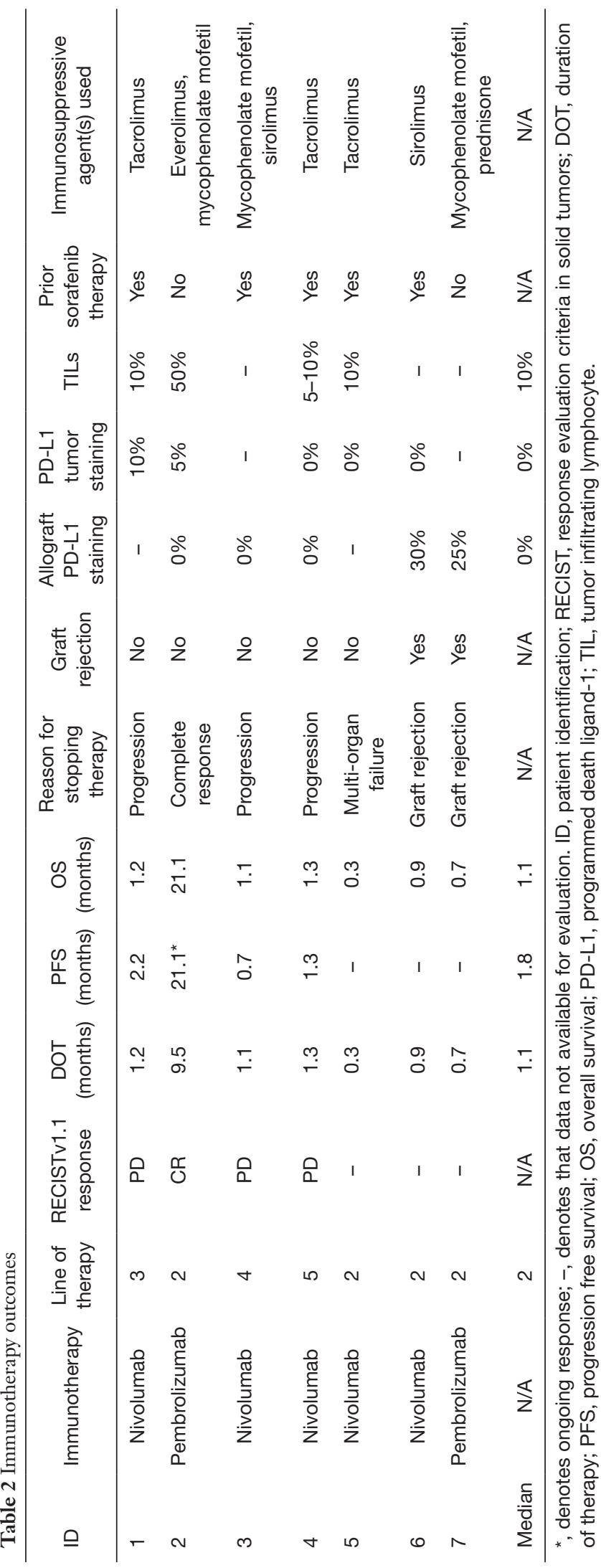

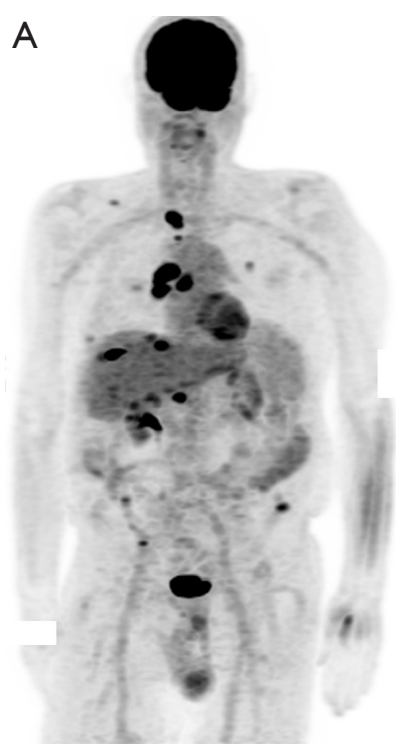

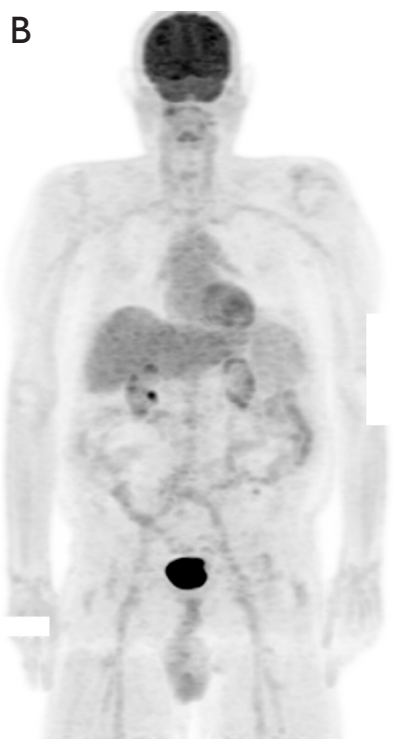

Figure $1 \mathrm{PET} / \mathrm{CT}$ scans of patient \#2. (A) PET/CT prior to immunotherapy in patient \#2; (B) PET/CT scan showing radiographic complete response in patient $\# 2$ after completing pembrolizumab treatment.

received an mTOR inhibitor for immunosuppression. In the patients who experienced graft rejection, one patient was treated with mycophenolate mofetil and prednisone, while the other patient received sirolimus. The 3 patients who received tacrolimus did not have graft rejection or response to therapy. The median duration of therapy with PD-1 inhibitors [1.1 (range, 0.3-9.5) months], PFS [1.8 (range, 0.7-21.1) months] and OS [1.1 (range, 0.3-21.1) months] were all brief in this cohort reflective of the advanced nature of disease in these patients (Table 2). Patient \#6 expired due to progression of his cancer. The natural history of his allograft rejection is unclear since he enrolled in hospice and did not have subsequent assessments. Patient \#7 is still undergoing treatment for his allograft rejection, but at the time of this report the patient's acute cellular rejection appears to be improving with treatments of thymoglobulin, mycophenolate mofetil, tacrolimus and prednisone.

\section{PD-L1 staining and TILs}

Five patients were evaluable for liver allograft lymphocyte PD-L1 expression. All three patients without allograft rejection had $0 \%$ allograft PD-L1 staining. However, both cases of allograft rejection in this cohort were found to have allograft lymphocyte PD-L1 expression with a median 

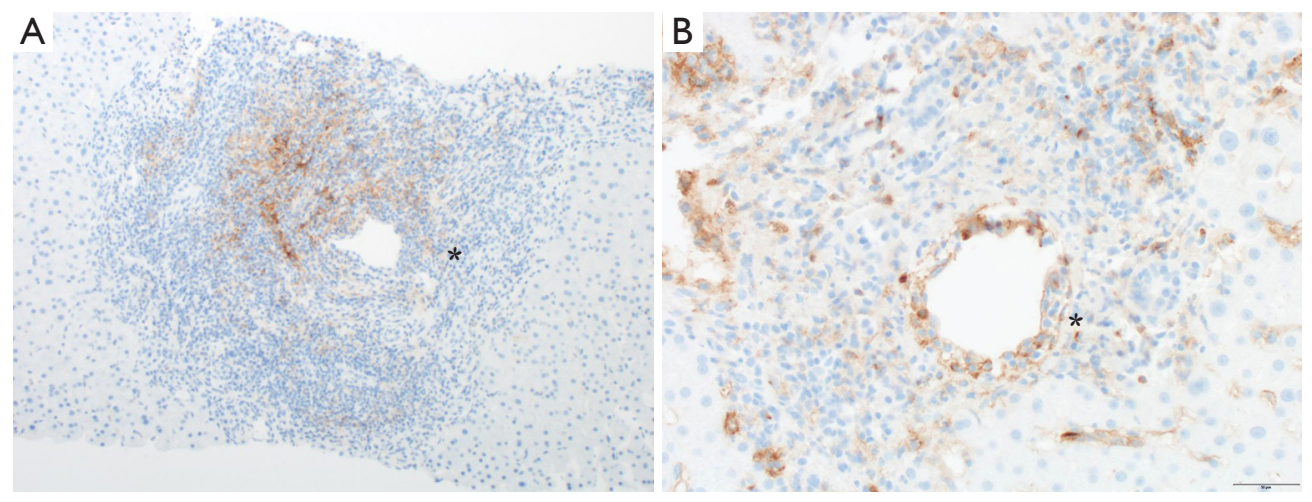

Figure 2 PD-L1 immunohistochemistry in liver allograft tissue near the portal vein in patient \#6 (A) (magnification $\times 100)$ and patient \#7 (B) (magnification $\times 200$ ). Brown staining represents PD-L1 expression in portal lymphocytes. Image (B) shows enrichment of PD-L1 lymphocyte staining in areas of endotheliitis. *, denotes the portal vein. PD-L1, programmed death ligand-1.

PD-L1 lymphocyte expression of $27.5 \%$ (range, $25-30 \%$ ) as shown in Figure 2. One case of allograft rejection (patient \#7) demonstrated enrichment of lymphocytes with PD-L1 expression $(>80 \%)$ in areas of endotheliitis.

Five patients had tumor samples that were evaluable for PD-L1 staining. Two of the five patients were found to have PD-L1 expression. The median tumor PD-L1 expression was $0 \%$ (range, $0-10 \%$ ). The patient who responded to PD-1 inhibition (patient \#2) had 5\% PD-L1 tumor staining. However, patient \#1 had 10\% PD-L1 tumor expression, but had PD. Patient \#4 did not have PD-L1 expression and had PD. Patient \#5 and \#6 did not have PD-L1 expression and were not evaluated for response to therapy.

Four patients had sufficient tumor tissue for TIL assessment. The median percentage of TILs was $10 \%$ (range, $0-50 \%$ ). The patient who responded to PD-1 inhibitor therapy (patient \#2) had both PD-L1 expression (5\%) and a high percentage of TILs (50\%). However, the patient who had PD-L1 expression (10\%), but a lower percentage of TILs (10\%) was found to have PD on PD-1 inhibitor therapy (patient \#1). Patient \#4 had no PD-L1 expression and a low percentage of TILs (5-10\%) and had PD. Assessment of PD-L1 expression and TILs are summarized in Table 2.

\section{Changes in liver laboratory studies, prognostic scores and tumor markers}

Acute cellular rejection was seen in two patients. The diagnosis of rejection was established based on a significant elevation of transaminases and in one case elevation of total bilirubin, without any significant change in albumin, or INR as shown in Table S1. Patient \#6 had grade 3 [Common Terminology Criteria for Adverse Events (CTCAE) version 4.03 classification] elevation of AST [460 units (U)/liter (L)] and ALT (433 U/L) at baseline. Only one other patient (patient \#1) started off with elevated AST (134 U/L) and ALT (253 U/L) levels, but these were lesser grades of AST (grade 0) and ALT (grade 2) elevations. All patients with HCC experienced an increase in AFP with a median rise of 1,000 nanograms $(\mathrm{ng}) /$ milliliter $(\mathrm{mL})$ and ranged from 1,000 to $214,082 \mathrm{ng} / \mathrm{mL}$.

\section{Discussion}

PD-1/PD-L1 inhibitor therapy in patients with a history of LT needs to be considered with a great deal of caution given the possibility of graft rejection. However, the effectiveness of immunotherapy in certain tumor types warrants the exploration of immunotherapy in LT patients. This small retrospective study provides preliminary insight into the possible outcomes of PD-1 inhibition in this population.

In this study, a single patient obtained a durable CR, while two patients developed graft rejection. The patient that responded was a patient with melanoma (patient \#2) and has achieved a sustained CR for over 21 months. However, none of the 5 HCC patients derived clinical benefit from PD-1 inhibitor therapy. This is far lower than the response rate reported in the literature for patients with SOT $(47.4 \%)$. However, the response rate reported in the literature is likely inflated due to publication bias towards positive results. There are several potential explanations 
Table 3 Summary of literature results and study cohort results

\begin{tabular}{|c|c|c|c|c|c|c|c|c|}
\hline Variables & $\begin{array}{c}\text { Liver } \\
\text { transplant } \\
\text { (literature) }\end{array}$ & $\begin{array}{c}\text { Renal \& heart } \\
\text { transplant } \\
\text { (literature) }\end{array}$ & $\begin{array}{l}\text { PD-1 inhibitors } \\
\text { (literature) }\end{array}$ & $\begin{array}{c}\text { CTLA-4 } \\
\text { inhibitors } \\
\text { (literature) }\end{array}$ & $\begin{array}{c}\text { PD-1 \& CTLA- } \\
4 \text { inhibitor } \\
\text { (literature) }\end{array}$ & $\begin{array}{l}\text { All literature } \\
\text { results }\end{array}$ & $\begin{array}{c}\text { Study } \\
\text { cohort (liver } \\
\text { transplant) }\end{array}$ & $\begin{array}{l}\text { Overall } \\
\text { (all results) }\end{array}$ \\
\hline $\begin{array}{l}\text { Median time to graft } \\
\text { rejection (days) }\end{array}$ & $13(n=2)$ & $8(n=5)$ & $13.5(n=6)$ & - & $8(n=1)$ & $8(n=7)$ & $24(n=2)$ & $19(n=9)$ \\
\hline $\begin{array}{l}\text { Median PFS } \\
\text { (months) }\end{array}$ & $3.8(n=10)$ & $8(n=11)$ & $8(n=11)$ & $5(n=7)$ & $8(n=3)$ & $7(n=21)$ & $1.8(n=4)$ & $6(n=25)$ \\
\hline $\begin{array}{l}\text { Median time to } \\
\text { transplant (years) }\end{array}$ & $6(n=11)$ & $11(n=15)$ & $9(n=14)$ & $8(n=8)$ & $11(n=4)$ & $8(n=26)$ & $3(n=7)$ & $8(n=33)$ \\
\hline
\end{tabular}

PFS, progression free survival; PD-1, programmed death protein-1; CTLA-4, cytotoxic T-lymphocyte-associated protein-4.

for the lack of clinical benefit, which includes the use of immunosuppression. However, the effect these agents have in preventing therapeutic benefit from PD-1 inhibitors is not clear. Interestingly, mTOR inhibitors were used in one of the patients who experienced graft rejection and the patient who responded to immunotherapy, which may suggest less potent suppression of the PD-1/PDL1 pathway. On the contrary, none of the patients on calcineurin inhibitors experienced a therapeutic response or graft rejection. Previous case reports have shown that patients can respond to cancer immunotherapy despite immunosuppression, including patient \#2 from this cohort of patients. Many patients in this cohort had advanced disease at the time of receiving PD-1 inhibition, which likely influenced both the tolerance and duration of therapy. The median duration of therapy was 1.1 months with the longest duration of therapy in HCC patients being 1.3 months. The short duration of therapy, differences in efficacies of checkpoint inhibitors between HCC and more responsive tumors such as melanoma and the small size of this cohort are additional likely contributors to the lack of observed clinical benefit from PD-1 inhibitors.

PD-L1 staining alone did not consistently predict response to PD-1 inhibitor therapy. While the only patient in this cohort with a response to PD-1 inhibition (patient \#2) had PD-L1 staining of 5\%, there was also a patient with $10 \%$ PD-L1 tumor staining that did not respond to therapy (patient \#1). Notably, patient \#2 had both PDL1 expression and a high percentage of TILs (50\%). We speculate that abundant TILs and PD-L1 expression in combination may be a more reliable predictor of response to PD-1 inhibitors compared to PD-L1 expression alone.

There are 15 reported cases of patients with a history of SOT who received PD-1 inhibitors (10,14-25). The rejection rate in these case reports was $33.3 \%$ as shown in Table 3. The rejection rate was similar in the 5 patients whom received both PD-1 inhibitors and CTLA-4 inhibitors with a graft rejection rate of 40\% (26-30). Eight patients had a history of LT and received PD-1 inhibitors; two of these patients developed graft rejection, which equates to a graft rejection rate of $25 \%$ (14-16). All case reports of PD-1 inhibitor therapy with SOT are summarized in Tables $S 2$ and S3. A similar rate of graft rejection occurred (25\%) in the 8 patients treated with CTLA-4 inhibitors alone as shown in Tables $S 4$ and $S 5$, including 4 patients with a history of LT (29,31-36). Preclinical models have suggested that CTLA- 4 contributes to induction of graft tolerance, but not to maintenance of graft tolerance, which may suggest a lower predisposition to graft rejection in patients receiving CTLA-4 inhibitors with a remote history of SOT $(37,38)$. All patients who received ipilimumab and experienced graft rejection were receiving only prednisone for immune suppression therapy. All patients on more potent immune suppression who received ipilimumab did not experience graft rejection. Therefore, inadequate immune suppression may have contributed to graft rejection in these ipilimumab cases.

The rate of graft rejection in our study was $28.6 \%$, which is very similar to the $33.3 \%$ graft rejection rate reported in previous case reports that received PD-1 inhibitors. Unlike the response rates to immunotherapy the short duration of therapy did not appear to influence our observed rate 
of rejection. Graft rejection appears to be an early PD-1 inhibitor adverse event and occurs earlier than most other autoimmune adverse events which typically peak between 6-14 weeks after initiating therapy (39). The median time to rejection reported in previous case reports is 8 days with a range of $5-63$ days $(14,18,19,23,25,27)$. Similarly, in our cohort the median time to graft rejection diagnosis was 24 days with a range of 20-28 days. The early occurrence of graft rejections likely mitigated the effect that the short duration of therapy had on graft rejection rates in this cohort.

It remains unclear which immunosuppression is most efficacious at reducing the risk for graft rejection with immune checkpoint inhibitor therapy. There were no graft rejections in the 3 patients who received calcineurin inhibitors. There were graft rejections in the patients who received mTOR inhibitors ( 1 out of 3 ) and mycophenolate mofetil ( 1 out of 3$)$. The reported rates in the literature of graft rejection in patients treated with mTOR inhibitors $(\mathrm{n}=8)$, calcineurin inhibitors $(\mathrm{n}=6)$, mycophenolate mofetil $(\mathrm{n}=4)$ and glucocorticoids alone $(\mathrm{n}=8)$ are $12.5 \%, 18.2 \%$, $0 \%$ and $75 \%$ respectively $(10,14-35)$. However, many of these cases received combinations of immune suppression medications. Consequently, it is difficult to ascertain the degree in which each individual immune suppressive agent contributes to preventing graft rejection. However, glucocorticoids by themselves do not appear to be effective in preventing graft rejection when receiving immune checkpoint inhibitors.

A recent report described two case reports of allograft liver rejection after receiving $\mathrm{PD}-1$ inhibition in patients whose allograft liver tissue demonstrated PD-L1 expression (14). However, our study is the first to observe clinical outcomes in LT patients with and without allograft PD-L1 expression who received PD-1 inhibitors. All reported LT cases, including our study, who lacked allograft lymphocyte PDL1 expression $(n=3)$ did not develop rejection while those with allograft lymphocyte PD-L1 expression ( $n=4)$ developed rejection. This finding should be confirmed in larger studies. However, if validated, allograft lymphocyte PD-L1 expression could function as a biomarker that predicts risk for graft rejection in SOT patients when using PD-1 inhibitors. A limitation of our assessment is that both patients who experienced rejection were tested for allograft lymphocyte PD-L1 expression after receiving PD-1 inhibitors.

\section{Conclusions}

There is very limited data for the use of PD-1/PD-L1 inhibitors in patients with LT and larger, prospective studies are needed to define the optimal patient selection and management of LT patients who receive PD-1 inhibitor therapy. In the meantime clinical benefit may be achieved with PD-1 inhibitor therapy despite immunosuppressive therapy. However, this benefit is counterbalanced by the risk of graft rejection and careful consideration of the riskbenefit ratio should occur prior to pursuing this option in patients with LT.

\section{Acknowledgements}

None.

\section{Footnote}

Conflicts of Interest: The authors have no conflicts of interest to declare.

Ethical Statement: The study was approved by the Mayo Clinic Institutional Review Board (No. IRB00000020) and informed consent waiver was granted by the IRB under 45 CFR 46.116 given the retrospective, minimal risk nature of the study.

\section{References}

1. Dempke WCM, Fenchel K, Uciechowski P, et al. Second- and third-generation drugs for immunooncology treatment-The more the better? Eur J Cancer 2017;74:55-72.

2. Riella LV, Watanabe T, Sage PT, et al. Essential role of PDL1 expression on nonhematopoietic donor cells in acquired tolerance to vascularized cardiac allografts. Am J Transplant 2011;11:832-40.

3. Tanaka K, Albin MJ, Yuan X, et al. PDL1 is required for peripheral transplantation tolerance and protection from chronic allograft rejection. J Immunol 2007;179:5204-10.

4. Ozkaynak E, Wang LQ, Goodearl A, et al. Programmed death-1 targeting can promote allograft survival. J Immunol 2002;169:6546-53.

5. Ito T, Ueno T, Clarkson MR, et al. Analysis of the role of negative $\mathrm{T}$ cell costimulatory pathways in CD4 and CD8 $\mathrm{T}$ cell-mediated alloimmune responses in vivo. J Immunol 2005;174:6648-56.

6. Starke A, Lindenmeyer MT, Segerer S, et al. Renal tubular PD-L1 (CD274) suppresses alloreactive human T-cell responses. Kidney Int 2010;78:38-47. 
7. Haverkos BM, Abbott D, Hamadani M, et al. PD-1 blockade for relapsed lymphoma post-allogeneic hematopoietic cell transplant: high response rate but frequent GVHD. Blood 2017;130:221-8.

8. Davids MS, Kim HT, Bachireddy P, et al. Ipilimumab for Patients with Relapse after Allogeneic Transplantation. N Engl J Med 2016;375:143-53.

9. Godfrey J, Bishop MR, Syed S, et al. PD-1 blockade induces remissions in relapsed classical Hodgkin lymphoma following allogeneic hematopoietic stem cell transplantation. J Immunother Cancer 2017;5:11.

10. Kittai AS, Oldham H, Cetnar J, et al. Immune Checkpoint Inhibitors in Organ Transplant Patients. J Immunother 2017;40:277-81.

11. Vilchez V, Shah MB, Daily MF, et al. Long-term outcome of patients undergoing liver transplantation for mixed hepatocellular carcinoma and cholangiocarcinoma: an analysis of the UNOS database. HPB (Oxford) 2016;18:29-34.

12. Huang $X$, Lu S. Impact of preoperative locoregional therapy on recurrence and patient survival following liver transplantation for hepatocellular carcinoma: a metaanalysis. Scand J Gastroenterol 2017;52:143-9.

13. El-Khoueiry AB, Sangro B, Yau T, et al. Nivolumab in patients with advanced hepatocellular carcinoma (CheckMate 040): an open-label, non-comparative, phase 1/2 dose escalation and expansion trial. Lancet 2017;389:2492-502.

14. Friend BD, Venick RS, McDiarmid SV, et al. Fatal orthotopic liver transplant organ rejection induced by a checkpoint inhibitor in two patients with refractory, metastatic hepatocellular carcinoma. Pediatr Blood Cancer 2017;64(12).

15. Varkaris A, Lewis DW, Nugent FW. Preserved Liver Transplant After PD-1 Pathway Inhibitor for Hepatocellular Carcinoma. Am J Gastroenterol 2017;112:1895-6.

16. Biondani P, De Martin E, Samuel D. Safety of an antiPD-1 immune checkpoint inhibitor in a liver transplant recipient. Ann Oncol 2018;29:286-7.

17. Barnett R, Barta VS, Jhaveri KD. Preserved RenalAllograft Function and the PD-1 Pathway Inhibitor Nivolumab. N Engl J Med 2017;376:191-2.

18. Boils CL, Aljadir DN, Cantafio AW. Use of the PD-1 Pathway Inhibitor Nivolumab in a Renal Transplant Patient With Malignancy. Am J Transplant 2016;16:2496-7.

19. Lipson EJ, Bagnasco SM, Moore J, et al. Tumor
Regression and Allograft Rejection after Administration of Anti-PD-1. N Engl J Med 2016;374:896-8.

20. De Toni EN, Gerbes AL. Tapering of Immunosuppression and Sustained Treatment With Nivolumab in a Liver Transplant Recipient. Gastroenterology 2017;152:1631-3.

21. Rammohan A, Reddy MS, Farouk M, et al. Pembrolizumab for metastatic hepatocellular carcinoma following live donor liver transplantation: The silver bullet? Hepatology 2018;67:1166-8.

22. Schvartsman G, Perez K, Sood G, et al. Immune Checkpoint Inhibitor Therapy in a Liver Transplant Recipient With Melanoma. Ann Intern Med 2017;167:361-2.

23. Ong M, Ibrahim AM, Bourassa-Blanchette S, et al. Antitumor activity of nivolumab on hemodialysis after renal allograft rejection. J Immunother Cancer 2016;4:64.

24. Wu CK, Juang GD, Lai HC. Tumor regression and preservation of graft function after combination with anti-PD-1 immunotherapy without immunosuppressant titration. Ann Oncol 2017;28:2895-6.

25. Owonikoko TK, Kumar M, Yang S, et al. Cardiac allograft rejection as a complication of $\mathrm{PD}-1$ checkpoint blockade for cancer immunotherapy: a case report. Cancer Immunol Immunother 2017;66:45-50.

26. Herz S, Hofer T, Papapanagiotou M, et al. Checkpoint inhibitors in chronic kidney failure and an organ transplant recipient. Eur J Cancer 2016;67:66-72.

27. Spain L, Higgins R, Gopalakrishnan K, et al. Acute renal allograft rejection after immune checkpoint inhibitor therapy for metastatic melanoma. Ann Oncol 2016;27:1135-7.

28. Alhamad T, Venkatachalam K, Linette GP, et al. Checkpoint Inhibitors in Kidney Transplant Recipients and the Potential Risk of Rejection. Am J Transplant 2016;16:1332-3.

29. Kuo JC, Lilly LB, Hogg D. Immune checkpoint inhibitor therapy in a liver transplant recipient with a rare subtype of melanoma: a case report and literature review. Melanoma Res 2018;28:61-4.

30. Qin R, Salama AKS. Report of ipilimumab in a heart transplant patient with metastatic melanoma on tacrolimus. Melanoma Manag 2015;2:311-4.

31. Lipson EJ, Bodell MA, Kraus ES, et al. Successful Administration of Ipilimumab to Two Kidney Transplantation Patients With Metastatic Melanoma. J Clin Oncol 2014;32:e69-71.

32. Morales RE, Shoushtari AN, Walsh MM, et al. Safety and efficacy of ipilimumab to treat advanced melanoma in 
the setting of liver transplantation. J Immunother Cancer 2015;3:22.

33. Ranganath HA, Panella TJ. Administration of Ipilimumab to a Liver Transplant Recipient With Unresectable Metastatic Melanoma. J Immunother 2015;38:211.

34. Dueland S, Guren TK, Boberg KM, et al. Acute liver graft rejection after ipilimumab therapy. Ann Oncol 2017;28:2619-20.

35. Jose A, Yiannoullou P, Bhutani S, et al. Renal Allograft Failure After Ipilimumab Therapy for Metastatic Melanoma: A Case Report and Review of the Literature. Transplant Proc 2016;48:3137-41.

36. Gastman BR, Ernstoff MS. Tolerability of immune

Cite this article as: DeLeon TT, Salomao MA, Aqel BA, Sonbol MB, Yokoda RT, Ali AH, Moss AA, Mathur AK, Chascsa DM, Rakela J, Bryce AH, Borad MJ. Pilot evaluation of PD-1 inhibition in metastatic cancer patients with a history of liver transplantation: the Mayo Clinic experience. J Gastrointest Oncol 2018;9(6):1054-1062. doi: 10.21037/jgo.2018.07.05 checkpoint inhibition cancer therapy in a cardiac transplant patient. Ann Oncol 2016;27:2304-5.

37. Judge TA, Wu Z, Zheng XG, et al. The role of CD80, CD86, and CTLA4 in alloimmune responses and the induction of long-term allograft survival. J Immunol 1999;162:1947-51.

38. Li W, Zheng XX, Kuhr CS, et al. CTLA4 engagement is required for induction of murine liver transplant spontaneous tolerance. Am J Transplant 2005;5:978-86.

39. Villadolid J, Amin A. Immune checkpoint inhibitors in clinical practice: update on management of immunerelated toxicities. Transl Lung Cancer Res 2015;4:560-75. 
Supplementary

Table S1 Change in laboratory data with immunotherapy

\begin{tabular}{|c|c|c|c|c|c|c|c|c|}
\hline ID & $\begin{array}{l}\text { Change in } \\
\text { Child Pugh }\end{array}$ & $\begin{array}{l}\text { Change in } \\
\text { MELD }\end{array}$ & $\begin{array}{l}\text { Change in } \\
\text { AFP (ng/mL) }\end{array}$ & $\begin{array}{c}\text { Change in } \\
\text { albumin }(g / d L)\end{array}$ & $\begin{array}{l}\text { Change in } \\
\text { Tbili (mg/dL) }\end{array}$ & $\begin{array}{l}\text { Change in } \\
\text { AST (U/L) }\end{array}$ & $\begin{array}{l}\text { Change in } \\
\text { ALT (U/L) }\end{array}$ & $\begin{array}{l}\text { Change in } \\
\text { INR }\end{array}$ \\
\hline 1 & 0 & +5 & $+1,000$ & -0.3 & 0 & +162 & +84 & +0.08 \\
\hline 2 & 0 & 0 & N/A & +0.3 & +0.1 & -4 & -7 & -0.2 \\
\hline 3 & +1 & 0 & $+214,082$ & -0.1 & 0 & +3 & +26 & +0.08 \\
\hline 6 & +2 & +5 & +64.6 & -1.1 & +0.2 & +900 & +846 & 0.18 \\
\hline 7 & +2 & +6 & $+44,767$ & -0.1 & +0.8 & 169 & +151 & +0.1 \\
\hline Median & +1 & +1 & $+1,000$ & -0.3 & +0.1 & +11 & +26 & +0.08 \\
\hline
\end{tabular}

ID, patient identification; MELD, model for end stage liver disease; AFP, alpha-fetoprotein; Tbili, total bilirubin; AST, aspartate transaminase; ALT, alanine transaminase; INR, international normalized ratio; ng/Ml, nanograms per milliliter; g/dL, grams per deciliter; mg/dL, milligrams per deciliter; U/L, units per liter. 
Table S2 Previously reported cases of PD-1 inhibitor exposure in liver transplant patients

\begin{tabular}{|c|c|c|c|c|c|c|c|c|c|c|c|c|}
\hline ID & Age & $\begin{array}{l}\text { Transplant to } \\
\text { immunotherapy } \\
\text { (years) }\end{array}$ & $\begin{array}{l}\text { Organ } \\
\text { transplant }\end{array}$ & Malignancy & Immunotherapy & $\begin{array}{c}\text { Number of } \\
\text { immunotherapy } \\
\text { doses }\end{array}$ & $\begin{array}{l}\text { Time to graft } \\
\text { rejection (days) }\end{array}$ & Immune suppression & $\begin{array}{l}\text { Organ } \\
\text { rejection }\end{array}$ & $\begin{array}{c}\text { Response to } \\
\text { immunotherapy }\end{array}$ & $\begin{array}{c}\text { PFS } \\
\text { (months) }\end{array}$ & Ref \\
\hline 1 & 62 & 6 & Liver & $\begin{array}{l}\text { Malignant peripheral } \\
\text { nerve sheath tumor }\end{array}$ & $\begin{array}{l}\text { Ipilimumab \& } \\
\text { pembrolizumab }\end{array}$ & $4 / 25$ & - & $\begin{array}{l}\text { Sirolimus, } \\
\text { mycophenolate mofetil }\end{array}$ & No & PR & $17^{\star}$ & (29) \\
\hline 2 & 20 & 4 & Liver & FL-HCC & Nivolumab & 2 & 19 & Sirolimus & Yes & - & - & (14) \\
\hline 3 & 14 & 3 & Liver & FL-HCC & Nivolumab & 1 & 7 & Tacrolimus & Yes & - & - & (14) \\
\hline 4 & 70 & 8 & Liver & $\mathrm{HCC}$ & Pembrolizumab & - & N/A & Tacrolimus & No & PD & 3 & (15) \\
\hline 5 & 54 & 13 & Liver & $\begin{array}{l}\text { Non-small cell } \\
\text { lung cancer }\end{array}$ & Nivolumab & 3 & $\mathrm{~N} / \mathrm{A}$ & $\begin{array}{l}\text { Tacrolimus, everolimus, } \\
\text { prednisone }\end{array}$ & No & PD & 1.5 & (16) \\
\hline 6 & 41 & - & Liver & $\mathrm{HCC}$ & Nivolumab & 15 & N/A & Tacrolimus & No & PD & 3.5 & (20) \\
\hline 7 & 35 & 20 & Liver & Melanoma & Pembrolizumab & 2 & $\mathrm{~N} / \mathrm{A}$ & Tacrolimus & No & $\mathrm{CR}$ & $6^{\star}$ & (22) \\
\hline 8 & 57 & 3 & Liver & $\mathrm{HCC}$ & $\begin{array}{l}\text { Pembrolizumab \& } \\
\text { sorafenib }\end{array}$ & 14 & $\mathrm{~N} / \mathrm{A}$ & $\begin{array}{l}\text { mTOR inhibitor, } \\
\text { tacrolimus }\end{array}$ & No & $\mathrm{CR}$ & $10^{\star}$ & (21) \\
\hline Median & 68 & 6 & N/A & N/A & $\mathrm{N} / \mathrm{A}$ & N/A & 13 & $\mathrm{~N} / \mathrm{A}$ & N/A & N/A & 6 & $\mathrm{~N} / \mathrm{A}$ \\
\hline
\end{tabular}

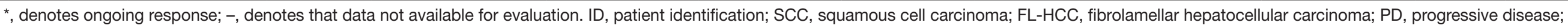
PR, partial response; Ref, references; N/A, not applicable.

Table S3 Previously reported cases of PD-1 inhibitor exposure in kidney and heart transplant patients

\begin{tabular}{|c|c|c|c|c|c|c|c|c|c|c|c|c|}
\hline ID & Age & $\begin{array}{c}\text { Transplant to } \\
\text { immunotherapy } \\
\text { (years) }\end{array}$ & $\begin{array}{l}\text { Organ } \\
\text { transplant }\end{array}$ & Malignancy & Immunotherapy & $\begin{array}{c}\text { Number of } \\
\text { immunotherapy } \\
\text { doses }\end{array}$ & $\begin{array}{l}\text { Time to graft } \\
\text { rejection (days) }\end{array}$ & Immune suppression & $\begin{array}{l}\text { Organ } \\
\text { rejection }\end{array}$ & $\begin{array}{l}\text { Response to } \\
\text { immunotherapy }\end{array}$ & $\begin{array}{c}\text { PFS } \\
\text { (months) }\end{array}$ & Ref \\
\hline 13 & 77 & 8 & Kidney & Melanoma & $\begin{array}{l}\text { Ipilimumab \& } \\
\text { nivolumab }\end{array}$ & $4 / 7$ & $\mathrm{~N} / \mathrm{A}$ & Prednisone, tacrolimus & No & PD & 5 & (26) \\
\hline 14 & 48 & 14 & Kidney & Melanoma & $\begin{array}{l}\text { Ipilimumab \& } \\
\text { nivolumab }\end{array}$ & $2 / 1$ & 8 & Prednisolone & Yes & - & 8 & $(27)$ \\
\hline 15 & 68 & 15 & Kidney & Melanoma & $\begin{array}{l}\text { Ipilimumab \& } \\
\text { pembrolizumab }\end{array}$ & $4 / 1$ & - & Prednisone & Yes & - & - & (28) \\
\hline 16 & 62 & - & Heart & Melanoma & $\begin{array}{l}\text { Ipilimumab \& } \\
\text { pembrolizumab }\end{array}$ & - & - & - & No & PD & - & (30) \\
\hline 17 & 74 & 5 & Kidney & SCC of lung & Nivolumab & 3 & 63 & Prednisone, cyclosporine & Yes & - & - & (18) \\
\hline 18 & 57 & 25 & Kidney & Cutaneous SCC & Pembrolizumab & - & 60 & Prednisone & Yes & PR & $8^{*}$ & (19) \\
\hline 19 & 69 & 14 & Kidney & Cutaneous SCC & Nivolumab & 11 & $\mathrm{~N} / \mathrm{A}$ & Prednisone, sirolimus & No & - & 8 & $(10)$ \\
\hline 20 & 70 & 5 & Kidney & Duodenum cancer & Nivolumab & 16 & $\mathrm{~N} / \mathrm{A}$ & Prednisone, sirolimus & No & PR & $8^{*}$ & (17) \\
\hline 21 & 72 & 10 & Heart & SCC of lung & Nivolumab & 12 & $\mathrm{~N} / \mathrm{A}$ & $\begin{array}{l}\text { Mycophenolate mofetil, } \\
\text { cyclosporine }\end{array}$ & No & - & $8^{*}$ & (10) \\
\hline 22 & 63 & 11 & Kidney & Melanoma & Nivolumab & 17 & 8 & Prednisone & Yes & PR & $8^{*}$ & (23) \\
\hline 23 & 61 & 8 & Kidney & Urothelial cancer & $\begin{array}{c}\text { Pembrolizumab, } \\
\text { bevacizumab, } \\
\text { cisplatin and } \\
\text { gemcitabine }\end{array}$ & 11 & $\mathrm{~N} / \mathrm{A}$ & $\begin{array}{l}\text { Mycophenolate mofetil, } \\
\text { tacrolimus }\end{array}$ & No & PR & $7^{\star}$ & (24) \\
\hline 24 & 49 & 19 & Heart & Cutaneous SCC & Nivolumab & 1 & 5 & Prednisone, tacrolimus & Yes & - & - & (25) \\
\hline Median & 68 & 11 & N/A & $N / A$ & N/A & N/A & 8 & $\mathrm{~N} / \mathrm{A}$ & $N / A$ & N/A & 8 & $\mathrm{~N} / \mathrm{A}$ \\
\hline
\end{tabular}

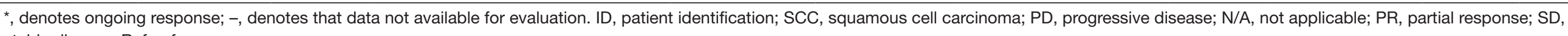
stable disease; Ref, references. 
Table S4 Previously reported cases of CTLA-4 inhibitor exposure in liver transplant patients

\begin{tabular}{|c|c|c|c|c|c|c|c|c|c|c|c|c|}
\hline ID & Age & $\begin{array}{l}\text { Transplant to } \\
\text { immunotherapy } \\
\text { (years) }\end{array}$ & $\begin{array}{c}\text { Organ } \\
\text { transplant }\end{array}$ & Malignancy & Immunotherapy & $\begin{array}{c}\text { Number of } \\
\text { immunotherapy } \\
\text { doses }\end{array}$ & $\begin{array}{l}\text { Time to graft } \\
\text { rejection } \\
\text { (days) }\end{array}$ & Immune suppression & $\begin{array}{l}\text { Organ } \\
\text { rejection }\end{array}$ & $\begin{array}{l}\text { Response to } \\
\text { immunotherapy }\end{array}$ & $\begin{array}{c}\text { PFS } \\
\text { (months) }\end{array}$ & Ref \\
\hline 9 & 59 & 8 & Liver & Melanoma & Ipilimumab & 4 & $\mathrm{~N} / \mathrm{A}$ & Tacrolimus & No & SD & 5 & (33) \\
\hline 10 & 67 & 8 & Liver & Melanoma & Ipilimumab & 4 & N/A & Sirolimus & No & PR & $4^{*}$ & (32) \\
\hline 11 & 62 & 6 & Liver & $\begin{array}{l}\text { Malignant peripheral nerve } \\
\text { sheath tumor-like melanoma }\end{array}$ & Ipilimumab & 4 & $\mathrm{~N} / \mathrm{A}$ & $\begin{array}{l}\text { Sirolimus, } \\
\text { mycophenolate mofetil }\end{array}$ & No & PD & 3 & \\
\hline 12 & 67 & 1.5 & Liver & Ocular melanoma & Ipilimumab & 1 & - & Prednisone & Yes & PD & 3 & (34) \\
\hline Median & 63 & 7 & N/A & N/A & N/A & 4 & - & N/A & N/A & N/A & 3.5 & $\mathrm{~N} / \mathrm{A}$ \\
\hline
\end{tabular}

Table S5 Previously reported cases of CTLA-4 inhibitor exposure in kidney and heart transplant patients

\begin{tabular}{|c|c|c|c|c|c|c|c|c|c|c|c|c|}
\hline ID & Age & $\begin{array}{l}\text { Transplant to } \\
\text { immunotherapy } \\
\text { (years) }\end{array}$ & $\begin{array}{l}\text { Organ } \\
\text { transplant }\end{array}$ & Malignancy & Immunotherapy & $\begin{array}{c}\text { Number of } \\
\text { immunotherapy } \\
\text { doses }\end{array}$ & $\begin{array}{l}\text { Time to graft } \\
\text { rejection (days) }\end{array}$ & $\begin{array}{l}\text { Immune } \\
\text { suppression }\end{array}$ & $\begin{array}{l}\text { Organ } \\
\text { rejection }\end{array}$ & $\begin{array}{l}\text { Response to } \\
\text { immunotherapy }\end{array}$ & $\begin{array}{c}\text { PFS } \\
\text { (months) }\end{array}$ & Ref \\
\hline 25 & 72 & 11 & Kidney & Melanoma & Ipilimumab & - & N/A & Prednisone & No & PR & $30^{*}$ & (31) \\
\hline 26 & 58 & 8 & Kidney & Melanoma & Ipilimumab & 4 & N/A & Prednisone & No & - & 6 & (31) \\
\hline 27 & 40 & 20 & Kidney & Ocular Melanoma & Ipilimumab & 2 & - & Prednisone & Yes & PD & - & (35) \\
\hline 28 & 69 & 15 & Heart & Melanoma & Ipilimumab & 4 & $\mathrm{~N} / \mathrm{A}$ & Tacrolimus & No & SD & 10 & (36) \\
\hline Median & 63 & 13 & $\mathrm{~N} / \mathrm{A}$ & $\mathrm{N} / \mathrm{A}$ & N/A & 4 & N/A & N/A & N/A & N/A & 10 & N/A \\
\hline
\end{tabular}

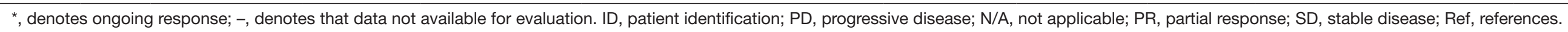

